\title{
Análise de agrupamento para a identificação e caracterização das propriedades fumageiras de Paraíso do Sul
}

\author{
Cluster analysis for the identification and characterization of south \\ paradise smoking properties
}

\author{
Gustavo do Nascimento Friedrich', Ivanor Müller", \\ Fernando de Jesus Moreira Junior"', Angela Pelegrin Ansuj'v', Jonas Pedro Fabris ${ }^{\vee}$
}

\begin{abstract}
RESUMO
A identificação dos sistemas de produção efetivamente usados pelos produtores é importante para subsidiar as instituições de pesquisa agropecuária e extensão rural na geração e transferência de tecnologias compatíveis com a realidade dos produtores. Este estudo teve como objetivo principal identificar e caracterizar os sistemas de produção de fumo no município de Paraíso do Sul através do uso da análise de agrupamentos. Após a análise unidimensional, algumas perguntas foram selecionadas com base na variabilidade entre as respostas e, a partir destas, construíram-se as variáveis necessárias para se proceder à análise multidimensional. A análise de agrupamentos mostrou-se um instrumento útil e adequado para a identificação de sistemas de produção em uso pelos produtores rurais.
\end{abstract}

Palavras-chaves: Agricultura familiar, Fumicultura, Análise de Agrupamento.

\begin{abstract}
The identification of the production systems effectively used by the producers is important to subsidize the agricultural research and extension institutions in the generation and transfer of technologies compatible with the reality of the producers. This study aimed to identify and characterize the smoke production systems in the municipality of Paraíso do Sul through the use of cluster analysis. After the onedimensional analysis, some questions were selected based on the variability between the answers and from these, the necessary variables were constructed to perform the multidimensional analysis. Cluster analysis proved to be a useful and suitable tool for the identification of production systems in use by rural producers.
\end{abstract}

Keywords: Family Farming, Tobacco Farming, Cluster Analysis.

\footnotetext{
'Universidade Federal de Santa Maria, Brasil; e-mail: gustavofriedrich@outlook.com;

"Universidade Federal de Santa Maria. Brasil. e-mail: ivanormuller@smail.ufsm.br;

III Universidade Federal de Santa Maria, Brasil; e-mail: fmjunior777@yahoo.com.br;

IV Universidade Federal de Santa Maria, Brasil; e-mail: angelaansuj@yahoo.com;

v Universidade Federal de Santa Maria. Brasil.e-mail: jpfabris@hotmail.com
} 


\section{INTRODUÇÃO}

A tecnologia gerada mediante os procedimentos convencionais de investigação agropecuária muitas vezes, não é apropriada às circunstâncias reais vivenciadas pelos pequenos produtores. Isto quer dizer, que a oferta tecnológica não é pertinente às condições físicas, bióticas, socioeconômicas e histórico-culturais que determinam a estrutura e o funcionamento da pequena agricultura. Neste sentido, se estabelece a complexidade do desafio de produzir tecnologia melhorada e adaptável ao pequeno produtor; requerendo então, uma investigação que se aproxime à realidade sistêmica.

Em virtude disso, as técnicas de análise estatística multivariada passam a ser vistas como ferramentas idôneas e essenciais para tipificação e classificação de pequenas propriedades por uma simples razão: o conceito de sistemas de pequenas propriedades é multivariado, no sentido de que é de sua essência a idéia de vários componentes ou subsistemas interagindo no tempo e no espaço com supra- sistemas de natureza diversa.

Segundo EMBRAPA (1980), existe uma carência de metodologias que possam agilizar e disponibilizar as informações sobre o conhecimento do uso e ocupação das terras e da tipologia dos sistemas de produção de maneira mais atual. Sendo que, o levantamento e a caracterização de sistemas de produção, de forma convencional, têm se limitado à escala da propriedade rural, geralmente com análise estatística univariada.

Neste sentido, dada a importância desta questão na metodologia investigativa e na extensão desses sistemas de produção têm-se a qualidade da resposta a esta necessidade evidenciando assim, uma alta influência sobre os resultados e a eficiência deste processo investigativo em geral.

Em razão disso, resolveu-se identificar e caracterizar os sistemas de produção de fumo do município de Paraíso do Sul através do uso de análise multivariada. 


\section{REVISÃO BIBLIOGRÁFICA}

\subsection{Metodologia para a tipificação de sistemas de produção agrícola}

Tal como requer toda aplicação de ferramentas analíticas estatísticas ou de modelos matemáticos, o marco conceitual é o primeiro passo necessário para a classificação de sistemas de produção agrícola. A construção desse marco teórico tem características muito especiais neste tipo de aplicação porque a evidência empírica demonstra a impossibilidade de desenhar um modelo teórico-conceitual universal para os efeitos de classificar sistemas de produção agrícola.

Segundo Berdegué et al. (1990), marco conceitual é simplesmente um modelo teórico qualitativo que consta, em um primeiro momento, das hipóteses sobre a estrutura, o funcionamento e a evolução do sistema de produção agrícola; sobre os objetivos, metas e habilidades dos produtores e sobre as relações entre o sistema de produção e seus supra e subsistemas.

A construção deste modelo se alimenta de três grandes insumos:

- a bagagem teórica e empírica acumulada pela equipe de investigação, dentro do qual, o conceito de multidimensionalidade de um sistema de produção agrícola aparece como um elemento chave a destacar.

- a definição dos objetivos gerais e específicos do projeto e do uso a que se destina a tipificação.

- a informação disponível sobre a região onde se realizará o projeto, sobre sua agricultura, economia, população, etc.

O enfoque de sistemas no desenho e desenvolvimento da investigação implica em uma análise integral dos componentes, o que, necessariamente, se traduz em uma matriz de funções multivariadas e de múltiplos processos. Esta multidimensionalidade inclui a tarefa de ordenar os sistemas de produção agrícola uma zona geográfica determinada, sempre que desse ordenamento responda a um objetivo funcional e reconheça a hierarquia dos sistemas. 
Esta visão integral se operacionaliza de duas maneiras:

- com o reconhecimento da hierarquia dos sistemas agrícolas, a partir do sistema objeto selecionado pra a classificação.

- com a materialização do marco conceitual de um conjunto de variáveis que represente os principais subsistemas e funções do sistema objeto de classificação, incluindo limitantes e possibilidades de operacionalização.

Uma vez identificado o sistema objeto, a análise hierárquica inclui o sistema imediatamente superior (suprasistema) e o imediatamente inferior (subsistema). Esta escala mínima da hierarquia permite entender as relações de dependência imediata do sistema estudado (sistema objeto) com aqueles níveis que o mantém com uma interação mais direta. Um exemplo, é a análise de sistema de produção agrícola com suas relações com o sistema da região e com os subsistemas tecnológicos que determinam a produção do sistema objeto.

A conformação dos níveis hierárquicos é subjetiva e, conseqüentemente, permite ser adaptada a cada problema de investigação com a finalidade de capturar os níveis requeridos para o sistema objeto. A definição arbitrária desta hierarquia e a determinação estrutural das inter-relações entre os níveis são as que finalmente determinam as variáveis específicas que se vai medir e analisar.

Um trabalho de zonificação, prévio a fase de tipificação pode ajudar a elaboração do marco teórico, em dois sentidos:

- para identificar, em uma região determinada, aqueles espaços que mostram condições mais favoráveis para a localização de um projeto de investigação ou desenvolvimento agropecuário.

- quando se deseja compreender as dinâmicas de desenvolvimento regional que podem ajudar a definir as orientações, limites e possibilidades do projeto.

A identificação propriamente dita dos sistemas de produção agrícola requer uma atenção especial por se tratar do sistema objeto que se quer tipificar e porque este nível é, normalmente, o sujeito da ação para a qual se determinam os grupos homogêneos. 
É neste nível que se materializa o marco conceitual das variáveis que explicam as relações entre subsistemas de produção agrícola e entre as unidades de produção e os fatores em nível de região que mais afetam a atividade de produção.

O conjunto de hipóteses se deve traduzir em uma série de variáveis que permitam capturar a informação a ser verificada. De alguma maneira, se pode decidir que este conjunto coerente e articulado de variáveis é a expressão operativa do marco conceitual. Estas variáveis constituem os critérios de classificação e traduzem o modelo hipotético dos sistemas de produção agrícola, pontualizando as características que se deve buscar nos sistemas de acordo com os objetivos que motivaram a sua tipificação. Em conseqüência, estas variáveis são as que, normalmente, se medem a nível de unidade de produção e são as que analisadas com a ajuda de técnicas estatísticas separam os sistemas de produção agrícola segundo a diferenciação no comportamento destas variáveis.

Independentemente das estratégias utilizadas para obter e organizar a informação mínima para formular o marco conceitual, é importante entender que este marco cumpre uma função normativa para a seleção do enfoque metodológico, das ferramentas analíticas e para a interpretação da tipologia que se quer construir. É importante ter bem clara a idéia do curto alcance da tipificação dos sistemas de produção agrícola: os tipos de sistemas representam um certo grau de homogeneização aplicável e utilizável dentro dos parâmetros incluídos na formulação do marco conceitual. Esta é a razão que impossibilita construir tipologias universais, ou de utilidade múltipla.

\subsection{Análise de Agrupamento}

A aplicação de Análise de Agrupamento tem finalidades bastante diferenciadas, tais como a determinação de objetos semelhantes num primeiro estágio de um esquema de amostragem estratificada, formulação de hipóteses sobre a estrutura dos dados e a determinação de esquemas de classificação Pereira (1999). Os métodos de análise de Agrupamento aparecem nas diversas áreas de estudos, por exemplo, botânica, zoologia, medicina, psicologia, sociologia, geografia, arqueologia, inteligência 
artificial, sinais emitidos por satélites, etc. Também aplicados nas mais diferentes finalidades de aplicações.

Segundo Johnson et al. (1992), a análise de agrupamento consiste em analisar a proximidade geométrica entre os objetos estudados. Neste tipo de análise são calculadas as distâncias entre os objetos estudados dentro do espaço multiplano constituído por eixos de todas as medidas realizadas (variáveis) e em seguida, os objetos são agrupados conforme a proximidade entre eles. Para Crivisqui (1996), a técnica de análise de agrupamento analisa as medidas de distância euclidiana e não tem representação gráfica. É utilizada quando se quer identificar grupos de características semelhantes, ou seja, quando se quer categorizar as observações levando em conta todas as medidas originais.

Os métodos de análise de agrupamentos (AA) são utilizados para separar um conjunto de objetos ou variáveis em grupos, onde os componentes dentro dos grupos apresentem características homogêneas e que estas sejam heterogêneas entre os componentes de grupos distintos (Silva, 1999).

O principal objetivo dos métodos de agrupamento é a construção de partições em um conjunto de elementos (indivíduos, variáveis), a partir de suas distancias dois a dois. A aplicação deste método a um conjunto dado de unidades de observação significa definir, neste conjunto, as classes entre as quais se distribuem os elementos, através de procedimentos destinados a definir a classe de indivíduos (similaridade) e inversamente a dissimilaridade (Costa, 2000).

Conforme Barroso (2003), análise de agrupamentos é o nome dado a um conjunto de técnicas utilizadas na identificação de padrões de comportamentos em bancos de dados através da formação de grupos homogêneos de casos. Para Ferreira (1996), a análise de agrupamento não considera o número de grupos, é realizada com base na similaridade e dissimilaridade. Esta análise tem o objetivo de agrupar objetos semelhantes conforme suas características ou variáveis. Outro procedimento consiste em verificar se um indivíduo com as coordenadas $A(2 ; 1)$ é mais parecido com $B(7 ; 1)$ do que com $C(4 ; 3,5)$. Na figura 1, tem-se uma situação em $A$ que é mais parecido com $B$ do que com C. 
Para fazer tal inferência estatística usou o conceito de distância euclidiana. Quando o número de variáveis é muito pequeno, é possível fazer uma inspeção visual para responder tal decisão.

Figura 1 - Dispersão entre três indivíduos mensurados com relação a duas variáveis quantitativas contínuas.

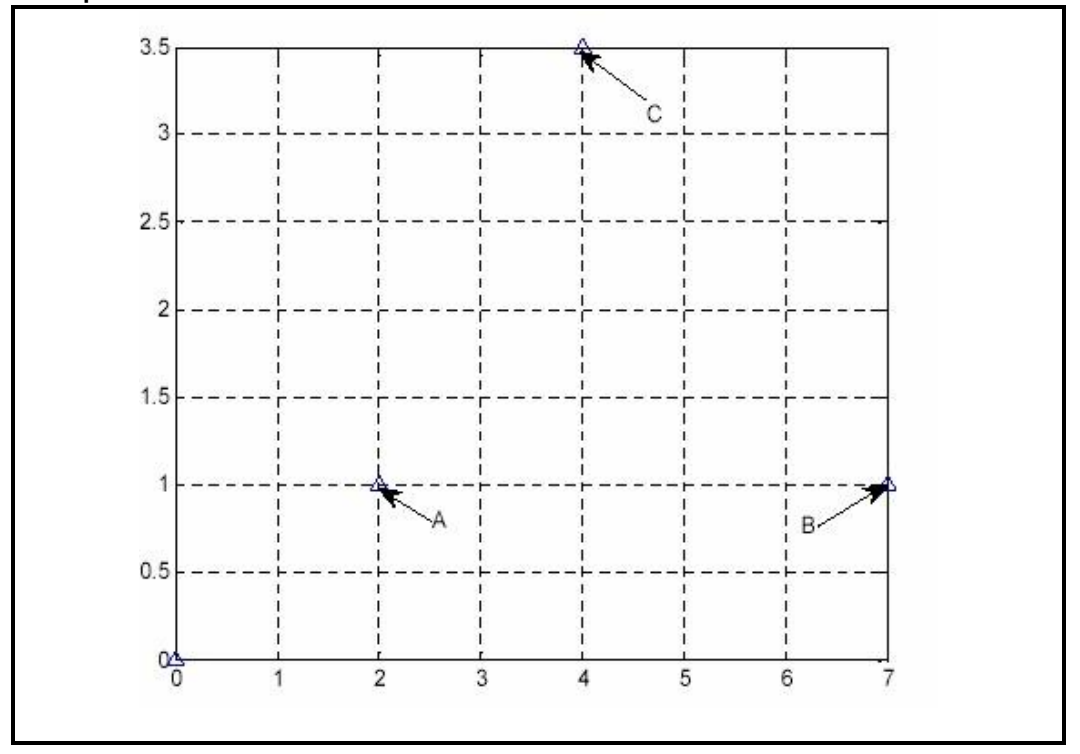

As seqüências resultantes das classificações são usualmente representadas sob forma de uma árvore de classificação chamada de dendograma. O ponto central é a escolha de uma linha de corte que indique, no dendograma, um conjunto significativo de grupos ou que coloque em evidencia os cortes naturais implícitos na estrutura de dados. Um possível corte deverá ser realizado quando a curva crescer mais rápido, havendo um salto entre os valores. Entretanto, a escolha deste corte ainda é feita de forma subjetiva (Silva, 1999).

Segundo Barroso (2003), as medidas de similaridade e dissimilaridade tem um papel importante quando se agrupam através de algoritmos. Define-se critério para avaliação dos grupos se eles estão próximos ou não. Existem dois tipos de medidas:

- medida de similaridade: quanto maior o valor, maior a semelhança entre os objetos;

- medida de dissimilaridade: quanto maior o valor, mais diferentes são os objetos. 
Em Ferreira (1996), há uma necessidade de especificar um coeficiente que indique uma proximidade entre os indivíduos. Para todos os casos verifica-se a natureza das variáveis se são discretas, contínuas ou binárias e a escala de medida se é nominal, ordinal, real ou razão.

Para Barroso (2003), para definir o número de grupos é necessário que se tenha algum conhecimento sobre os dados como características ou pode se basear no resultado da análise. Quanto à formação de grupos pode-se definir o tipo de algoritmo utilizado na sua identificação. Na validação do agrupamento as variáveis possuem comportamento diferenciado nos diversos grupos, e para que possa aplicar técnicas inferenciais para compara-las. No final do processo para interpretar os grupos podemse caracterizar os grupos formados usando estatísticas descritivas.

Segundo Ferreira (1996), as técnicas de agrupamento podem ser hierárquicas e não-hierárquicas. Os métodos de agrupamento hierárquicos têm início com um grupo separado. Primeiramente, os objetos mais similares são agrupados formando um único grupo. Eventualmente, o processo é repetido, e com o decréscimo da similaridade, todos os subgrupos são agrupados, formando um único grupo com todos os objetos (Ferreira, 1996).

Segundo Barroso (2003), para formação destes grupos são utilizados alguns métodos hierárquicos de agrupamento:

- Método do Vizinho Mais Próximo: usa a menor distância entre um elemento de $\underline{X}_{1}$ e um elemento de $\underline{X}_{2}$.

- Método do Vizinho Mais Longe: é definido pela maior distância entre um elemento de X1 e um elemento de X2.

- Método das Médias das Distâncias: calcula-se a média das distâncias entre os elementos de X1 e os de X2.

- Método do Centróide: define a coordenada de cada grupo sendo a média das coordenadas de seus objetos. Uma vez obtida essa coordenada, denominada centróide, a distância entre os grupos é obtida através do cálculo das distâncias entre as centróides.

- Método Ward: a alocação de um elemento a um grupo é feita de modo a minimizar uma medida de homogeneidade interna. 
Para Barroso (2003), a Correlação Cofenética é uma medida de validação utilizada nos métodos de agrupamentos hierárquicos. Comparam-se as distâncias observadas entre os objetos e as distâncias previstas a partir de um processo de agrupamento. Para um bom agrupamento as distâncias previstas podem respeitar a ordem determinada pelas distâncias observadas, ou seja, quando duas observações estão próximas, espera-se que a distância prevista entre elas seja pequena. Em uma avaliação da ocorrência deste comportamento, define-se correlação cofenética como sendo a correlação entre as distâncias efetivas observadas e as previstas. Por exemplo, quando houver uma correlação cofenética em torno de 0,95, indica-se um agrupamento de boa qualidade.

\subsection{Tipificação (agrupamento) de produtores rurais}

O enfoque metodológico de sistêmicos (Teoria de Sistemas), segundo Magalhães et al. (1997), permite estabelecer uma relação entre as ciências agrícola e social, entendidas como a ciência da produção agropecuária e a ciência do desenvolvimento, inseridas num contexto social e econômico. Um sistema pode ser definido como um conjunto de elementos ou componentes que interagem entre si. Compreender a realidade em termos de sistema é considerar todos os componentes ligados aos elementos humanos, edáficos, biológicos e mecânicos que podem ser trabalhados em diferentes níveis de agregação. O sistema de produção é definido como a combinação das produções e dos fatores de produção da propriedade, englobando os sistemas de cultivo e de pecuária, manejados dentro dos limites de ocupação espacial da área explorada, dados pelas quantidades disponíveis de terra, mão de obra e capital. O sistema de cultivo é um subsistema do sistema de produção e consiste em uma superfície de terreno tratada de maneira homogênea (Magalhães et al., 1997). Para a tipificação, Magalhães (op. cit.) considera que o processo de produção agrícola se desenvolve em unidades produtivas de formas diversas, desde grandes empresas capitalizadas com mão-de-obra estritamente assalariada até unidades familiares, cada uma caracterizada por condições agroeconômicas e sociais e por lógicas específicas. Então, para se levar em conta esta diversidade de lógicas e de condições de produtores, 
é necessário tipificá-los (isto é, agrupá-los) em função de seus sistemas de produção, ou seja, formar grupos de propriedades homogêneas segundo algumas variáveis socioeconômicas e de produção (Echeverria, 1999).

Mas, para se conseguir uma tipificação - o mais homogênea possível, considerando que geralmente as regiões são muito heterogêneas- o processo de amostragem exige cuidados a fim de que as características da totalidade de sua população sejam preservadas. Dessa forma, torna-se conveniente dividir essa população heterogênea em sub-populações homogêneas, chamadas estratos. Este processo de definição de amostragem apropriada pode ser facilitada pela utilização de imagens de satélites e pela aplicação de fichas de levantamento (questionários) adequadas à região em estudo e pelo uso de técnicas estatísticas multivariadas para o tratamento de dados (EMBRAPA, 1991).

Porém, para garantir uma maior homogeneidade possível e garantir precisão que os dados amostrais representem bem a população em sua totalidade, a amostra aleatório e estratificada ter-se-á que cobrir um porcentual bem representativo para tipologia de produtores. Para alguns autores este porcentual é bem variável. Em trabalhos de tipificação e caracterização de sistemas de produção, alguns autores chegaram a cobrir um porcentual variável: Miranda \& Cabral (1984) trabalharam com esforço amostral de 14,3\% dos pequenos produtores de Juazeiro-BA; 17,6\% em UauáBA e 13,4\%, em Euclides da Cunha-BA; para Itararé-SP, 15,9\% dos pequenos agricultores e em Arraias-TO, o porcentual foi de 15\% (EMBRAPA, 1991).

Também Miranda et al. (1995), em pesquisa sobre o levantamento do uso das terras com imagem de satélite Landsat e acompanhamento das propriedades visando a descrição técnica dos sistemas de produção vinculados às unidades de uso das terras, trabalhou com uma amostra de 15,70\% em Campinas -SP.

Também, com o enfoque sobre a importância de levantamento de dados primários via questionários, Martin et al. (1998) enfatiza que, para completar o diagnóstico do setor rural de um município, que servirá de referência para estabelecer os cenários futuros e analisar as alternativas de desenvolvimento, torna- se necessário levantar informações junto aos produtores por meio de questionários. E para a 
realização desses levantamentos deve-se considerar os recursos econômicos e o tempo disponível. Para Martin (op. cit.), as alternativas possíveis, considerando vantagens e desvantagens são as seguintes: a) realizar o levantamento valendo-se de entrevistas diretas com pessoas-chave do município (técnicos, lideranças atuais e antigas de agricultores, etc.) e fazer entrevistas com representantes dos diversos segmentos. Vantagens: envolve um menor número de pessoas, permite maior agilidade na avaliação e conclusão das análises. Desvantagem: a representatividade das entrevistas que pode levar a erros, impedindo tanto uma análise adequada quanto um maior detalhamento dos sistemas produtivos, dificultando a quantificação das variáveis relevantes para elaboração de cenários e alternativas; b) realizar uma pesquisa por intermédio de amostras de produtores, envolvendo um número reduzido de agricultores, escolhidos aleatoriamente entre as diversas comunidades. Neste caso, será possível separar produtores por tamanho de imóvel rural e obter informações qualitativas e quantitativas representativas da agricultura municipal. Vantagem: menor tempo e custo para realização. Desvantagem: indisponibilidade de um cadastro de produtores que permita determinar a amostra, reduzindo erros que, do contrário, podem comprometer todo o levantamento e seus resultados; c) realizar um censo de todos os imóveis rurais do município, permitindo caracterizar a situação real dos agricultores e da agricultura municipal, uma vez que não apresenta erros elevados que podem ocorrer nas pesquisas amostrais. A grande desvantagem deste método é o tempo necessário e o aporte de recursos (Martin et al., 1998).

Segundo Echeverria (1999), municípios que adotaram estes tipos de levantamentos estão conscientes de que terão em mãos um poderoso instrumento para embasar um qualificado diagnóstico municipal. Também segundo este autor, o diagnóstico quantitativo rural é apenas uma etapa de um processo de planejamento municipal mais qualificado, que tem como produto importante o Plano Municipal de Desenvolvimento Rural.

Portanto, fica evidenciada a importância e a necessidade, pelas análises e experiências preliminares relatadas nesta última abordagem de revisão bibliográfica, de levantamentos dos sistemas de produção por enfoque sistêmico. E que esta 
metodologia de tipificação e classificação de propriedades agrícolas é uma ferramenta que pode levar à eficiência e à eficácia da pesquisa e do planejamento e desenvolvimento rural em uma região. Com este método é possível definir a diversidade existente na agricultura, planejar e delimitar ações e recomendações de tecnologia gerada pela pesquisa, elaborar listas das unidades de produção representativas, delimitar e selecionar com precisão as populações alvo para uma determinada inferência de resultados de desenvolvimento rural, fazer monitoramento e análises espaço-temporais em propriedades representativas, oferecer bases para diferenciar linhas de experimentação, dentre outras. E para facilitar o levantamento dos sistemas de produção pode-se partir da identificação do uso da terra e dos parcelares utilizando-se de sensoriamento remoto pela sua visão sinótica, com a possibilidade de atualizações constantes. Em áreas de pequenos agricultores onde há grande variabilidade no tipo de uso e nos parcelares de modo intensivo a utilização do sensoriamento remoto com alta resolução espacial, torna-se importante opção.

\section{METODOLOGIA}

\subsection{Caracterização Geral da Área}

A colonização do Estado teve início em 1824, sendo que o primeiro período caracterizou-se por projetos oficiais e o segundo, pela colonização privada, iniciada em 1850. Pode-se dividir o período da colonização européia em três fases. Na primeira fase, de 1824 a 1890, foram implantadas as chamadas "Colônias Velhas" em um raio de 200 Km de Porto Alegre. A segunda fase, de 1890 a 1920, corresponde à implantação das "Colônias Novas" e se encerra quando o Rio Grande do Sul suspende a política de colonização por falta de recursos. Na terceira fase predomina a colonização privada e ocorre a incorporação das últimas áreas de florestas do Estado, localizadas na região do Alto Uruguai (Silva Neto \& Frantz, 1994).

Na região serrana do COREDE-Central ocorre a implantação de duas grandes colônias oficiais (provinciais, com o apoio do Império), a Colônia Alemã de Santo Ângelo, na região dos atuais municípios de Agudo e Paraíso do Sul, e a Colônia de Silveira Martins (atualmente conhecida como Quarta Colônia Italiana), nos municípios de Santa 
Maria e Silveira Martins. É a partir da expansão dessas duas colônias, com a criação de núcleos e também de colônias particulares, que se povoará todo o Rebordo da Serra Geral da Região.

Por volta de 1860, com a ampliação da Colônia de Santo Ângelo, atual município de Agudo, da qual Paraíso do Sul fazia parte, foi realizada a medição de terras e o povoamento de grande parte da área atual do município. Segundo Abich (2001), por volta de 1863, estabeleceram-se muitos colonos alemães com seus descendentes. No ano de 1880 vieram os imigrantes italianos que ocuparam as regiões do Campestre e região serrana.

Desde a época da colonização, nos fins do século passado, o núcleo básico da área emancipada é conhecido como Paraíso do Sul.

O processo de emancipação do município de Paraíso do Sul iniciou-se na década de 80 e foi concluído em 12/05/1988 pela Lei Número 8622, no governo do então governador Pedro Simon.

Com isso, a área do município passa a ser constituída pelos distritos de Rincão da Porta e Paraíso do Sul, pertencentes ao município de Cachoeira do Sul.

O nome do novo município passou a chamar-se Paraíso do Sul, onde a atual Vila Paraíso do Sul passa a denominar-se simplesmente Vila Paraíso.

O município de Paraíso do Sul, localiza-se entre as Coordenadas Geográficas $29^{\circ}$ $51^{\prime \prime} 05^{\prime \prime}$ a $29^{\circ} 33^{\prime} 31^{\prime \prime}$ de latitude sul e $53^{\circ} 02^{\prime} 02^{\prime \prime}$ a $53^{\circ} 13^{\prime} 31^{\prime \prime}$ de longitude oeste. $\mathrm{O}$ município está localizado na região central do Estado do Rio Grande do Sul, na região fisiográfica de Depressão Central e Planalto Meridional Brasileiro, estando grande parte da área do município localizada na transição Planalto- Depressão, ou seja, o rebordo do Planalto. Possui uma área de $342 \mathrm{~km}^{2}$ com uma população de 7.197 habitantes, sendo $22,4 \%$ considerada urbana e $77,6 \%$ rural (IBGE, 2001).

Paraíso do Sul limita-se ao norte com os municípios de Agudo e Cerro Branco, ao sul com os municípios de Agudo e Restinga Seca, a leste com Novo Cabrais e Cachoeira do Sul e a oeste com Agudo. 
Conforme Abich (2001), a base da economia do município se assenta na agropecuária, ou seja, no setor primário da economia, destacando-se a cultura do fumo e arroz irrigado. A maioria dos estabelecimentos rurais é de pequenas propriedades.

Na região sul do município de Paraíso do Sul, sobre as áreas sedimentares e planícies aluviais, encontram-se as maiores propriedades rurais, com intensa mecanização agrícola onde predomina o cultivo do arroz irrigado. Essa área apresenta condições favoráveis para este tipo de cultura por ser uma área de relevo plano e grande disponibilidade de água para irrigação, destacando-se o Rio Jacuí. Em alguns locais onde o relevo é mais ondulado cultiva-se também fumo e milho.

Na região norte do município pratica-se a policultura, ou seja, são plantados vários tipos de cultivos agrícolas numa pequena extensão de terras. Cultiva-se fumo, milho, feijão, amendoim, mandioca, entre outros. O fumo é o principal produto agrícola comercializado, sendo a principal fonte de renda para a maioria dos agricultores desta região do município.

Nesta porção do município também são encontradas as menores propriedades rurais, utilizando-se basicamente mão-de-obra familiar e pouca mecanização agrícola.

Na pecuária predomina a criação de gado bovino para o fornecimento de carne e leite e para os serviços na lavoura com tração animal. São criadas também aves, suínos e ovinos, principalmente, para o sustento da família.

Com relação às condições climáticas, baseando-se na Classificação de Köppen, o município de Paraíso do Sul enquadra-se no Clima Subtropical úmido do tipo Cfa, significando:

- C: inverno frio com temperaturas médias do mês mais frio em torno de $8^{\circ} \mathrm{C}$, com geadas freqüentes de maio ao setembro.

- f: nenhuma estação seca, úmido todo o ano, com chuvas bem distribuídas durante todo ano.

- a: verão quente, com temperatura média do mês mais quente superior a $22^{\circ} \mathrm{C}$.

A precipitação pluviométrica média fica em torno de 1600 mm, ocorrendo precipitações durante todos os meses do ano. 
Com relação a hidrografia, a rede hidrográfica no município pertence à Bacia do Rio Jacuí, sendo que o mesmo passa na porção sul do município, fazendo o limite com o município de Restinga Seca. O Rio Jacuí recebe como principais afluentes o Arroio da Porta e o Arroio Barriga que correm dentro da área do município sendo muito importante para o abastecimento e irrigação das lavouras. Além desses, destacam-se, também, o Arroio Paraíso, Arroio Contenda, Arroio Preguiça, Arroio Paraguassú e o Arroio Boa Vista, bem como inúmeros pequenos córregos, riachos e sangas. No que se refere ao relevo do município, segundo Abich (2001), é constituído de áreas planas e onduladas na porção sul e áreas mais declivosas e fortemente onduladas na porção norte, pois grande parte do município localiza-se na zona de transição entre o Planalto Meridional Brasileiro, constituído de rochas vulcânicas e sedimentares e a Depressão Central formada por rochas sedimentares.

A área do município abrange dois compartimentos do relevo, o Planalto Meridional Brasileiro, subdividido em Topo e Rebordo, e a Depressão Central, subdividida em áreas de coxilhas e planícies aluviais. Em relação à vegetação, sua distribuição está associada às condições climáticas e litológicas da região. As matas nativas encontram-se, em grande parte, na região do Topo e Rebordo do Planalto. Nos locais mais planos esta vegetação já foi devastada, cedendo lugar para a agricultura. Grande parte dessas florestas também foi devastada em conseqüência de sua utilização intensa como fonte de energia (lenha), necessária para a secagem do fumo, cultura predominante em áreas de minifúndio. A área do município que abrange a Depressão Central com relevo mais plano é constituída por pontos de reflorestamento, por campos nos locais suavemente ondulados cobertos com vegetação rasteira e por lavouras nas áreas planas e nas planícies aluviais.

\subsection{Região em estudo e fonte de dados}

Os dados foram coletados através da aplicação de 177 questionários do tipo cross-section, distribuídos de forma aleatória entre as propriedades rurais produtoras de fumo de Paraíso do Sul.

Neste trabalho, foi possível a utilização de amostragem probabilística, pois estava disponível um mapa com os limites de todas as propriedades do município. De posse 
desse mapa, foi atribuído um número a cada propriedade e, foram amostradas 30\% do total de 592 propriedades rurais de Paraíso do Sul que possuem o fumo como atividade produtiva.

O questionário utilizado serviu para fazer um levantamento de informações como quais as atividades econômicas estão vinculadas a produção de fumo do município e condições de vida como educação, relações com o meio-ambiente, informações sobre a estrutura familiar, tipo de trabalho realizado pela família, quais os recursos disponíveis dentro da propriedade (abastecimento de luz, água, telefonia), os tipos de associações e organizações às quais o agricultora participa, estrutura da propriedade, financiamentos, mão-de-obra utilizada, benfeitorias, maquinário, divisão da unidade de produção, produção animal, produção vegetal e agroindústria caseira. Desta forma, tem-se uma visão geral de como se organizam e estruturam os estabelecimentos rurais produtores de fumo, buscando entender as heterogeneidades e identificar demandas por grupos de produtores, segundo suas condições específicas.

\subsection{Procedimento e definição das variáveis utilizadas}

Dentre os instrumentos de análise multivariada, o que melhor se presta para os fins a que se propõe este trabalho é a Análise de Agrupamento. Na definição dos agrupamentos foi utilizado o Método de Ward, que é um método hierárquico aglomerativo e que exige a utilização do quadrado da distância euclidiana como medida de semelhança entre as observações. A aplicação de modelos multivariados neste trabalho busca estratificar produtores de fumo em grupos homogêneos e diferenciados entre si, cujas características de produção, em conjunto, representam sistemas de produção distintos.

Uma vez estratificados os produtores, o perfil dos grupos passou a ser descrito e comparado utilizando-se análises tabulares. Essa descrição considerou vários aspectos dentro de um sistema de produção de fumo, quais sejam quantidade plantada, quantidade colhida, preço médio recebido, mecanização, mão- de-obra familiar, parcelismo, outros cultivos e produção animal. 
As variáveis utilizadas foram as seguintes:

tipo $=$ tipo de fumo

se Burley, a variável vale 1;

se Burley/Estufa, a variável vale 2;

se Estufa, a variável vale 3.

num_lav = número de lavouras de fumo

quant_plantada = quantidade plantada, em número de

pés. quant_colhida = quantidade de fumo colhida, em arrobas.

preço $=$ preço médio recebido por arroba.

milho = área plantada de milho, em hectares.

num_cultivos = número de cultivos além do fumo e do milho.

socio = se a produção de fumo é feita em sociedade, a variável vale 1. Senão. ela vale 0.

tracao $=$ se o produtor possui, pelo menos, um trator, a variável vale 1. Senão, vale 0 .

bov_corte $=$ rebanho $($ número de cabeças) de bovinos de

corte. bov_leite = rebanho (número de cabeças) de bovinos de leite.

suinos = rebanho (número de cabeças) de suínos.

tipo_upa = tipo de unidade de produção,

se é própria/individual, a variável vale 1;

se é posse, a variável vale 2;

se é arrendamento, a variável 3;

se é parceria, a variável vale 4;

se é sociedade, a variável vale 5 .

financiamento = valor monetário;

upa = tamanho da unidade de produção, em

hectares.

mdo = quantidade de mão-de-obra familiar, em

UTH. 
Observação: A unidade de trabalho-homem (UTH) utilizada na variável mdo foi calculada baseada na tabela de Lima et al. (1995), saber:

- de 10 anos até 13 anos corresponde a 50\% de umaUTH;

- de 14 anos até 17 anos corresponde a 65\% de umaUTH;

- de 18 anos até 59 anos corresponde a 100\% de uma UTH;

- acima de 60 anos corresponde a 75\% de uma UTH.

\section{RESULTADOS E DISCUSSÕES}

Nesta parte é feita a descrição do perfil tecnológico de cada grupo representando sistemas de produção diferentes. Inicialmente, realizou-se uma análise de agrupamento para verificar os grupos formados no dendograma, ou seja, aquelas unidades de produção que possuírem características semelhantes irão formar grupos homogêneos.

Na Figura 2 é apresentado o dendograma formado a partir da matriz inicial de observações, mediante a técnica de Análise de Agrupamento. Esses grupos foram definidos pelo traçado de uma linha paralela horizontal, denominada "Linha Fenon". Optou-se por traçar esta linha entre as alturas $2 \times 10^{10}$ e $4 \times 10^{10}$, que representam as distâncias euclidianas de ligação entre as unidades de produção em estudo. Observase a formação de quatro grupos distintos.

O Grupo I é representado por 3 unidades de produção, sendo que a produção de fumo é exclusivamente do tipo Burley. Apresentam uma quantidade plantada ao redor de 25.000 plantas, o que corresponde a uma área de aproximadamente 1 hectare. Devido a pequena área plantada, o número de lavouras não é superior a 2. O milho é cultivado em sucessão ao fumo, isto é, nas mesmas áreas (o milho da "safrinha"). A mecanização é exclusivamente animal. A produção de fumo não é feita em sociedade. Com relação a produção animal, esta destina-se exclusivamente ao consumo familiar. O preço médio recebido foi de $R \$ 42,00$ para as 3 unidades de produção deste grupo. Observou-se, também, neste grupo, a presença de outros cultivos como a batatinha e a produção de hortigranjeiros.

O Grupo II é representado por 19 unidades de produção, sendo que 80 \% destas cultivam fumo do tipo Estufa. A quantidade plantada em $90 \%$ das unidades de 
produção deste grupo fica em torno de 3,5 ha, o que corresponde a 80.000 plantas. Apresentam em média até 3 lavouras de fumo. O preço recebido por arroba fica em torno de $\mathrm{R} \$ 40,00$. Em 60 \% das unidades de produção o cultivo do fumo é feito em sociedade. A tração mecanizada é encontrada em $26 \%$ das propriedades.

Figura 2 - Dendograma com as 177 unidades de produção, utilizando o método Ward de agrupament

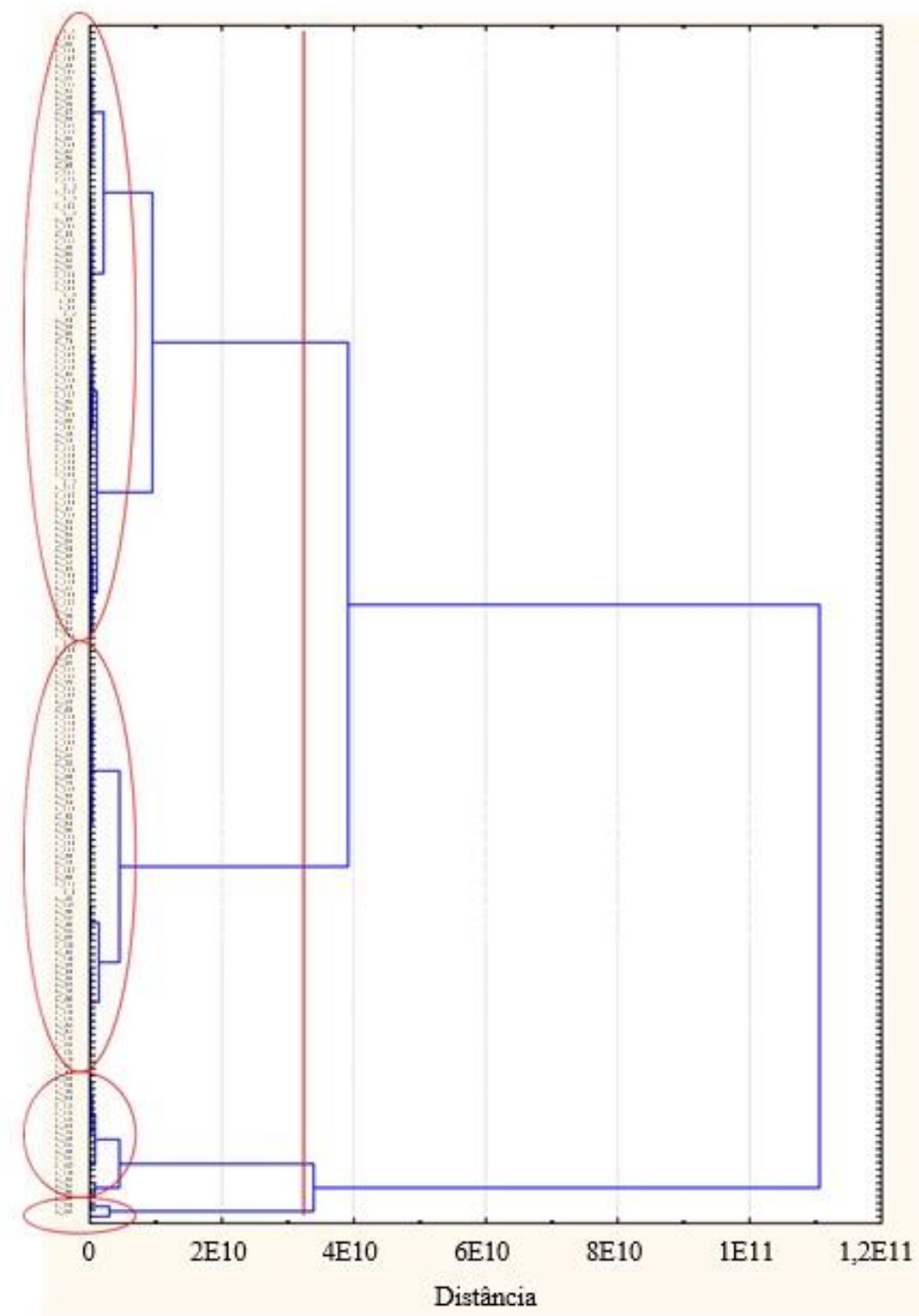

Neste grupo, a produção de fumo é feita na forma de monocultura, sendo pouco significativo a presença de outros cultivos. Devido as maiores áreas, tem-se produção em parceria em $74 \%$ das propriedades. Sendo que a presença de meeiros, também, encontra-se em igual proporção. Assim, como no Grupo I, o milho é cultivado em sucessão ao fumo na "safrinha" No cadastramento dos agricultores, foram raros os que declararam comercializar o milho, sendo que, quando feito, foi feito em pequena escala, 
ou seja, apenas 7,5 \% das unidades de produção comercializam o milho, com uma média de 50 sacas por unidade de produção.

O Grupo III representa mais da metade (51 \%) do total de propriedades analisadas, o que corresponde a 90 unidades de produção. Neste grupo, 97 \% das propriedades cultivam fumo do tipo Estufa. A quantidade colhida, em $75 \%$ das propriedades fica em torno de 450 arrobas por hectare. Apenas $30 \%$ das unidades de produção apresentam o fumo cultivado em parceria. A área cultivada com milho fica em torno de 10 ha em $64 \%$ das propriedades. Neste grupo, a suinocultura aparece como atividade complementar em $20 \%$ das propriedades.

No Grupo IV, correspondendo a 65 unidades de produção, observou-se que 20 \% das propriedades possuem os dois tipos de fumo, Burley e Estufa. Neste grupo, $70 \%$ das propriedades cultivam mais de 60.000 pés de fumo (mais de 3,5 hectares), onde é possível perceber um acentuado decréscimo na produtividade: a diferença entre os agricultores que cultivam até 1,5 hectares para os que cultivam mais de 3,5 hectares é de 58,7 arrobas/hectare. Ou seja, os agricultores de menor área têm uma produtividade 48,7 \% maior em relação aos de áreas maiores. Com relação ao preço médio recebido, não há variações como seria de se esperar, pois a perda de produtividade é acompanhada por uma significativa perda de qualidade. Entretanto, os piores preços são justamente dos pequenos produtores, o que pode ser um indicativo de que a "versão" dos agricultores de que o preço é estabelecido através de "politicagem" pode estar correta, isto é, os maiores agricultores têm um maior poder de barganha junto às fumageiras.

\section{CONCLUSÕES}

A análise de agrupamentos mostrou-se um instrumento útil e adequado para a identificação de sistemas de produção de fumo em uso pelos agricultores de Paraíso do Sul. A análise permitiu a identificação de quatro grupos de produtores de fumo em Paraíso do Sul. A produção de fumo Burley, geralmente é associada a outros cultivos, enquanto o fumo de Estufa é cultivado na forma de monocultura. A cultura que mais 
está associada ao cultivo do fumo de Estufa é o milho de safrinha, cultivado em sucessão ao fumo, beneficiando-se, assim, da sobra da adubação.

O cultivo de fumo é uma atividade tipicamente explorada por estabelecimentos familiares. Além de ser intensiva em mão-de-obra, exige dedicação e cuidados especiais para que não haja perdas na qualidade e produtividade.

Com o aumento da área, constatou-se um acentuado decréscimo na produtividade, sendo que a diferença entre os agricultores que cultivam até 1,5 hectares para os que cultivam mais de 3,5 hectares é de 58,7 arrobas/hectares. Ou seja, os agricultores de menor área têm produtividade 48,7 \% maior em relação aos de área maior.

Como cultivo de fumo é exigente em mão-de-obra, o aumento da produtividade e a conseqüente perda em qualidade acaba não afetando o preço recebido. Os piores preços são justamente dos pequenos produtores, isto ocorre devido aos maiores produtores terem um maior poder de barganha junto aos produtores.

A possibilidade de se analisar os dados considerando áreas homogêneas com relação a características de solo e relevo poderá fornecer bases mais consistentes para as conclusões sobre os sistemas de produção de fumo em Paraíso do Sul. 


\section{REFERÊNCIAS}

$\mathrm{ABICH}$, J. Mapeamento e análise do uso da terra no município de Paraíso do Sul RS através de fotografias aéreas. 2001, 57 f. Monografia (Especialização em Interpretação de Imagens Orbitais e Suborbitais) - Universidade Federal de Santa Maria, Santa Maria, 2001.

BARROSO, L.P. Análise Multivariada. 48a Reunião da RBRAS e 10o SEGRO - 7 a -Lavras MG. Departamento de Ciências e Exatas. Universidade Federal de Lavras, 2003.

BERDEGUÉ, J.; ESCOBAR, G. Tipificacion de sistemas de produccion agricola. Santiago, Chile: Rede Internacional de Metodologia de Investigación de Sistema de Producción, 1990. p. 284.

COSTA, S. A atividade carbonífera no sul de Santa Catarina e suas conseqüências sociais e ambientais, abordadas através de análises estatísticas mulivariadas. Florianópolis, 2000. Tese de doutorado em engenharia de produção, Universidade Federal de Santa Catarina - UFSC, $174 \mathrm{p}$.

CRIVISQUI, E. M. Iniciación al análisis de datos a partir de ejemplos. PRESTA Programme de recherche et d'enseignment en statistique appliquée, Université Libre de Bruxelles, Belgique, Apostila, 194 p. 1996.

ECHEVERRIA, L. C. C. R. Conhecimento da realidade rural. Agropecuária Catarinense, Santa Catarina, v. 12, n. 1, p. 43, mar. 1999.

EMBRAPA. (Brasília, DF). PRONAPA - Programa Nacional de Pesquisa Agropecuária. Brasília, 1980. $117 \mathrm{p}$.

EMBRAPA MONITORAMENTO POR SATÉLITE. Introdução às aplicações do sensoriamento remoto no monitoramento da agricultura: apostila de treinamento. Campinas, jun. 1991. 11 p. (Métodos Quantitativos na Avaliação das Atividades Agrícolas, 16).

FERREIRA, D. F. Análise Multivariada. Lavras, MG.Departamento de Exatas. apostila 400 pg. Universidade Federal de Lavras. 1996.

LIMA, A. J. P.; BASSO, N.; NEUMANN, P. S.; SANTOS, A. C.; MÜLLER, A. G. Administração da unidade de produção familiar: modalidades de trabalho com agricultores. ljuí: UNIJUÍ, 1995. 176 p.

MAGALHÃES, M. M de; BAZIN, F.; CARMO, M. S. do; SALLES, J. T. A. de O.; BERGAMASCO, S. M. P .P.; COMITRE, V. Banco de dados e enfoque sistêmicos em estudo de microbacias hidrográficas. In: WORKSHOP DO PROJETO PIRACEMA, 3., 1997, Nazaré Paulista. Anais... Piracicaba: CENA/USP, 1997. p. 58-64. 
MARTIN, N. B.; OTAN, M. N.; SERRA, R.; ÂNGELO, J. A. Subsídios paraelaboração de plano diretor agrícola municipal. Informações Econômicas, São Paulo, v. 28, n. 4, p. 33-45, abr. 1998.

MIRANDA, E. E. de; CABRAL, J. R. F. Caracterização da repartição espacial dos pequenos produtores de Euclides da Cunha, Juazeiro e Uauá, Salvador-BA. Bahia: EMATER/Embrapa-CPATSA, 1984. p. 30, il. (Embrapa-CPATSA. Pesquisa e Desenvolvimento, 3).

MIRANDA, E. E. de; DOURADO, A. J.; GUIMARÃES, M.; MANGABEIRA, J. A.; MIRANDA, J. R. Sistema de informaciones geograficas como instrumento complementario para la evaluacion de sistema de producción sostenibles: informe final. Campinas: ECOFUERZA Investigación y Desarrollo/UNICAMP- NUCATE/Embrapa-NMA, 1995. 220 p., il.

PEREIRA, J.C. Análise de dados qualitativos: estratégias metodológicas para as ciências da saúde, humanas e sociais. $2^{\mathrm{a}}$ edição. São Paulo: Editora da Universidade de São Paulo, 1999.

SILVA, E. Proposta de avaliação coletiva de imóveis: aplicação aos imóveis do tipo apartamento na cidade de Blumenau - Santa Catarina. Florianópolis, 1999. Dissertação de mestrado em engenharia civil, Universidade Federal de Santa Catarina UFSC, $116 \mathrm{p}$.

SILVA NETO, B. \& FRANTZ, T. R. Avaliação e Caracterização Sócio-Econômica dos Sistemas Agrários do Rio Grande do Sul. Relatório de Pesquisa RS-Rural - Estudo especial. DEAG/UNUJUí, ljuí, 2001. 188 p. 